\title{
Limited effects of intravenous paracetamol on patent ductus arteriosus in very low birth weight infants with contraindications for ibuprofen or after ibuprofen failure
}

\author{
Daniëlla W. E. Roofthooft ${ }^{1}$ • Ingrid M. van Beynum ${ }^{2}$ • Johan C. A. de Klerk ${ }^{1}$. \\ Monique van Dijk ${ }^{1,3}$ • John N. van den Anker ${ }^{3,4}$ - Irwin K. M. Reiss ${ }^{1}$ - Dick Tibboel ${ }^{3}$. \\ Sinno H. P. Simons ${ }^{1}$
}

Received: 25 February 2015 /Revised: 4 April 2015 / Accepted: 8 April 2015 / Published online: 30 April 2015

(C) The Author(s) 2015. This article is published with open access at Springerlink.com

\begin{abstract}
Finding the optimal pharmacological treatment of a patent ductus arteriosus (PDA) in preterm neonates remains challenging. There is a growing interest in paracetamol as a new drug for PDA closure. In this prospective observational cohort study, we evaluated the effectiveness of intravenous paracetamol in closing a PDA in very low birth weight infants with a hemodynamically significant PDA who either did not respond to ibuprofen or had a contraindication for ibuprofen. They received high-dose paracetamol therapy $(15 \mathrm{mg} / \mathrm{kg} / 6 \mathrm{~h}$ intravenous) for 3-7 days. Cardiac ultrasounds were performed before and 3 and 7 days after treatment. Thirty-three patients were included with a median gestational age of $25^{1 / 7}$ weeks (IQR 1.66), a median birth weight of $750 \mathrm{~g}$ (IQR 327), and a median postnatal age of 14 days (IQR 12). Paracetamol was ineffective in $27 / 33$ patients $(82 \%)$. Even more, after previous exposure to ibuprofen, this was even $100 \%$.
\end{abstract}

Conclusion: In this study, paracetamol after ibuprofen treatment failure was not effective for PDA closure in VLBW infants. From the findings of this study, paracetamol treatment for PDA closure cannot be recommended for infants with a postnatal age $>2$ weeks. Earlier treatment with paracetamol for PDA might be more effective.

\section{What is known:}

- The ductus arteriosus fails to close after birth in 30 to $60 \%$ of prematurely born neonates and is a significant cause of morbidity and mortality in these infants.

- Paracetamol gained importance as an alternative drug in PDA closure. What is new:

- Paracetamol for PDA closure after ibuprofen treatment failure was not effective in $V L B W$ infants.

- Effect of paracetamol on PDA closure was observed when given as primary treatment.
Daniëlla W. E. Roofthooft

d.roofthooft@erasmusmc.nl

Ingrid $\mathrm{M}$. van Beynum

i.vanbeynum@erasmusmc.nl

Johan C. A. de Klerk

j.deklerk@erasmusmc.nl

Monique van Dijk

m.vandijk.3@erasmusmc.nl

John N. van den Anker

jvandena@cnmc.org

Irwin K. M. Reiss

i.reiss@erasmusmc.nl
Dick Tibboel

d.tibboel@erasmusmc.n

Sinno H. P. Simons

s.simons@erasmusmc.nl

1 Department of Pediatrics, Division of Neonatology, Erasmus MC - Sophia Children's Hospital, Room Sp2463, Wytemaweg 80, 3015 CN Rotterdam, The Netherlands

2 Department of Pediatric Cardiology, Erasmus MC - Sophia Children's Hospital, Rotterdam, The Netherlands

Intensive Care and Department of Pediatric Surgery, Erasmus MC - Sophia Children's Hospital, Rotterdam, The Netherlands

4 Department of Pediatric Pharmacology, University Children's Hospital, Basel, Switzerland 
Keywords Paracetamol · Patent ductus arteriosus · VLBW infants $\cdot$ Ibuprofen contraindication $\cdot$ Ibuprofen treatment failure

$\begin{array}{ll}\text { Abbreviations } \\ \text { hSPDA } & \begin{array}{l}\text { Hemodynamically significant patent } \\ \text { ductus arteriosus }\end{array} \\ \text { IQR } & \text { Interquartile range } \\ \text { LA/Ao ratio } & \begin{array}{l}\text { Left atrial to aortic root ratio } \\ \text { Left pulmonary artery }\end{array} \\ \text { NPA } & \text { Necrotizing enterocolitis } \\ \text { NSC } & \text { Non-steroidal anti-inflammatory drugs } \\ \text { PDA } & \text { Patent ductus arteriosus } \\ \text { VLBW } & \text { Very low birth weight }\end{array}$

\section{Introduction}

The ductus arteriosus fails to close after birth in 30 to $60 \%$ of prematurely born infants [16]. This condition — patent ductus arteriosus (PDA) - is associated with a prolonged ventilation need and carries an increased risk of morbidity (i.e., necrotizing enterocolitis, chronic lung disease) and even mortality [10, 15, 18]. Pharmacological closure with non-steroidal anti-inflammatory drugs (NSAIDs), mainly ibuprofen and indomethacin, is currently the standard of care [27]. NSAIDs are not effective in around $30 \%$ of patients, however, and can have side effects such as gastrointestinal bleeding and perforation, diminished platelet aggregation, hyperbilirubinemia, and transient renal function impairment [22, 23]. Moreover, NSAIDs are contraindicated in a considerable proportion of newborns, notably those with renal failure, intracerebral hemorrhage, gastrointestinal problems, and thrombocytopenia. If NSAIDs fail or are contraindicated, the only currently available solution is surgical ligation, which is associated with the risks of cardiothoracic surgery and impaired neurological outcome [17]. Therefore, alternative pharmacological interventions are needed.

Paracetamol has been suggested as an alternative drug for PDA closure [21]. More than 10 observational and retrospective studies have described oral or intravenous high-dose paracetamol treatment with varying effectiveness $[1,8,9,11,12$, 19, 21, 26, 29] (see Table 1). Two recent prospective randomized controlled trials comparing oral paracetamol with ibuprofen both showed a slightly favorable effect of paracetamol (closure rate 81.2 versus $78.8 \%$ for ibuprofen) [5]. The other trial by Oncel et al. even showed a higher closure success rate in the paracetamol group ( 97.5 versus $95 \%$ in the ibuprofen group) after a maximum of two courses of ibuprofen or paracetamol [20].

After publication of the first studies on paracetamol and PDA closure, we added intravenous paracetamol to our PDA treatment guideline. However, the results in the first patients did not match the high closure rates of other studies, and only
$20 \%$ of patients did not need further PDA treatment after paracetamol [24]. Based on the promising results of other published studies, we decided to continue paracetamol treatment for PDA closure in preterm infants with ibuprofen contraindications or ibuprofen treatment failure.

In the current study, we describe the evaluation of the efficacy of intravenous paracetamol on PDA closure in very low birth weight (VLBW) infants admitted to our hospital.

\section{Methods}

In a prospective observational, single center study performed from December 2012 until September 2014, at the level III NICU of the Erasmus MC-Sophia Children's Hospital in Rotterdam, the Netherlands, we included all neonates with a gestational age of less than 28 weeks and a birth weight of less than $1500 \mathrm{~g}$, diagnosed with a hemodynamically significant patent ductus arteriosus (hsPDA) using clinical and cardiac ultrasound evaluation. Findings in the first nine patients in the current study were also presented in a preliminary report in 2014 [4].

The first drug of choice in our department for PDA treatment was intravenous ibuprofen (Neobrufen ${ }^{\mathcal{C}}$; Pedea (C), a single daily dose for 3 days $(10 \mathrm{mg} / \mathrm{kg}$ on the first day, $5 \mathrm{mg} / \mathrm{kg}$ on the second and third days), and a repeated 3-day course if closure was not yet obtained. Paracetamol (Perfalgan $\mathcal{C}$; BristolMeyers Squibb) was given if two courses of ibuprofen had no effect or if ibuprofen was contraindicated. Intravenous paracetamol $15 \mathrm{mg} / \mathrm{kg}$ every $6 \mathrm{~h}(60 \mathrm{mg} / \mathrm{kg} /$ day $)$ was administered for a minimum of 3 days and a maximum of 7 days.

Based on the indication for paracetamol, we created three groups. Group A: ibuprofen contraindicated and paracetamol as first drug of choice (primary contraindication); group B: development of a contraindication for ibuprofen during treatment with ibuprofen as first choice and switch to paracetamol (incomplete ibuprofen); and group C: two complete courses of ibuprofen failed to achieve closure and switch to paracetamol (complete ibuprofen) (see Fig. 1).

Contraindications for ibuprofen treatment were active intracerebral hemorrhage, thrombocytopenia or other known clotting disorders, severe sepsis, suspected or confirmed necrotizing enterocolitis (NEC), intestinal perforation, liver and kidney function disorders (oliguria $<1.0 \mathrm{ml} / \mathrm{kg} / \mathrm{h}$, serum creatinine $>110 \mu \mathrm{mol} / \mathrm{l}$ ) and severe hyperbilirubinemia.

Echocardiographic examination was performed by the echocardiosonographer or pediatric cardiologist before the start of paracetamol treatment, after 3 days and after 7 days. Measurements included ductus diameter, PDA diameter/LPA (left pulmonary artery) diameter, and LA/ Ao (left atrial to aortic root) ratio. Two-dimensional color Doppler echocardiography was performed using a Vivid- 
Table 1 Literature review on PDA treatment with paracetamol

\begin{tabular}{|c|c|c|c|c|c|c|c|}
\hline Author & $\begin{array}{l}\text { Dose } \\
(\mathrm{mg} / \mathrm{kg} / \text { day })\end{array}$ & $\begin{array}{l}\text { Treatment } \\
\text { interval (h) }\end{array}$ & Route & $\begin{array}{l}\text { Treatment } \\
\text { PCM (days) }\end{array}$ & $\begin{array}{l}\text { Gestational } \\
\text { age (weeks) }\end{array}$ & $\begin{array}{l}\text { PN age start } \\
\text { PCM (days) }\end{array}$ & $\begin{array}{l}\text { Patients that achieved ductal } \\
\text { closure/no surgical ligation }\end{array}$ \\
\hline 1. Hammerman 2011 & 15 & 6 & Oral & Max. 7 & $26-29^{6 / 7}$ & $3-35$ & $5 / 5$ \\
\hline 2. Yurttutan 2013 & 15 & 6 & Oral & Max. 6 & $26-30$ & $3-7$ & $5 / 6$ \\
\hline 3. Oncel 2013 & 15 & 6 & Intravenous & $3-6$ & $24-29$ & $2-15$ & $10 / 10$ \\
\hline 4. Alan 2013 & 15 & 6 & Intravenous & Max. 19 & $26^{2 / 7}-33^{5 / 7}$ & $8-19$ & $0 / 3$ \\
\hline 5. Özmert 2013 & 15 & 6 & Oral & $3-6$ & $23-32$ & $20-47$ & $5 / 7$ \\
\hline 6. Sinha 2013 & 15 & 8 & Oral & 2 & $27-33$ & $4-7$ & $10 / 10$ \\
\hline 7. Kessel 2013 & 15 & 6 & Oral & $3-11$ & $26-30$ & $?$ & $7 / 7$ \\
\hline 8. Jasani 2013 & 15 & 6 & Oral & $2.3-4.3$ & $28.5-31.1$ & & $2.6-8.9$ \\
\hline 9. Dang 2013 RCT & 15 & 6 & Oral & 3 & $31.2 \pm 1.8$ & & $65 / 80$ \\
\hline \multirow[t]{2}{*}{ 10. Oncel 2013 RCT } & 15 & 6 & Oral & $3-6$ & $\leq 26$ & $2-3$ & $12 / 13$ \\
\hline & 15 & 6 & Oral & $3-6$ & $<28$ & $2-3$ & $22 / 23$ \\
\hline \multirow[t]{2}{*}{ 11. Tekgunduz 2014} & 15 & 6 & Intravenous & 1 & 29 & 3 & $0 / 1^{\mathrm{a}}$ \\
\hline & 10 & 8 & Intravenous & $1-4$ & $24-31$ & $2-9$ & $10 / 12^{b}$ \\
\hline 12. Nadir 2014 & 15 & 6 & Oral & Max. 7 & $24-27$ & $2-22$ & $4 / 7$ \\
\hline \multirow[t]{3}{*}{ 13. el-Khuffash 2014} & 15 & 6 & Oral & 2 & $26-33$ & $14-56$ & $0 / 5$ \\
\hline & 15 & 6 & Oral & 7 & $26-30$ & $8-35$ & $6 / 7$ \\
\hline & 15 & 6 & Intravenous & $2-5$ & $26-32$ & $3-41$ & $9 / 9$ \\
\hline 14. Terrin 2014 & 7.5-15 max. 60 & $4-6$ & Intravenous & 3 & $26 \pm 2$ & $2.8 \pm 1.2$ & $6 / 8$ \\
\hline 15. Roofthooft 2014 & 15 & 6 & Intravenous & $3-7.5$ & $23^{6 / 7}-26^{4 / 7}$ & $3-33$ & $6 / 33$ \\
\hline 16. el-Khuffash 2015 & 15 & 6 & Intravenous & Max. 6 & $24.6-27.9$ & $16-39$ & $24 / 30$ \\
\hline
\end{tabular}

${ }^{\mathrm{a}}$ Transaminases elevated: paracetamol treatment stopped after three doses, ductal closure with oral ibuprofen

${ }^{\mathrm{b}}$ Ductal closure of two remaining PDAs with oral ibuprofen after paracetamol

S6 (GE Health Care) ultrasound system equipped with a $10-\mathrm{MHz}$ transducer.

Cardiac ultrasound studies were done at the bedside by different echocardiosonographers, and measurements were checked by one pediatric cardiologist (I. M. v B.). HsPDA closure was defined as no flow through the duct. An open duct with diameter $<1.5 \mathrm{~mm}$, without significant left-toright shunt, PDA:LPA diameter $<0.5$ and LA/Ao ratio $<1.4$ was defined as small PDA and not hemodynamically significant. HsPDA was defined as a ductal diameter of $>2.0 \mathrm{~mm}$, PDA:LPA diameter $>0.8$ and/or LA/Ao ratio $>1.6$.

\section{Statistical analysis}

Patient characteristics are presented as medians (IQR: interquartile range) in case of non-normally distributed variables and as means (standard deviations) in case of normally distributed variables. PDA diameters, PDA:LPA ratio and LA/ Ao ratio before, during, and after treatment with paracetamol were compared using paired $t$ tests. Fisher exact tests were used in case of categorical variables. Data analyses were performed with SPSS version 21.0 (SPSS Inc.). A $p$ value of 0.05 was set as statistically significant.

\section{Results}

A total of 33 VLBW infants with a median gestational age of $25^{1 / 7}$ weeks (range $23^{6 / 7}-26^{6 / 7}$, IQR 1.66 ) and a median birth weight of $750 \mathrm{~g}$ (range 365-1130, IQR 327) were included. Intravenous paracetamol was started at a median postnatal age of 14 days (IQR 12). Background characteristics and clinical outcome are shown in Table 2.

Median duration of paracetamol treatment was 6 days (IQR 3 ); the median cumulative dose was $360 \mathrm{mg}$ (IQR 180). Ductal closure or no hsPDA after treatment was achieved in six of the 33 patients (18\%). In total, 23 patients $(76.7 \%)$ needed surgical ligation for hsPDA with clinical symptoms. Findings in the three different groups (see Fig. 1) are detailed below.

Patients in group A (=primary contraindication for ibuprofen; $N=13,39.4 \%$ ) received the first dose of paracetamol after a median of 12 (IQR 11.5) postnatal days and the median duration of the course was 6 (IQR 3) days. In six patients (46\%), the ductus arteriosus was closed or not hemodynamically significant after paracetamol and further treatment was not indicated. Two of the seven patients who did not respond to paracetamol treatment were successfully treated with ibuprofen (one and two courses, respectively) afterwards because the contraindication for ibuprofen had disappeared. Surgical ligation was performed in the other five (54\%). 


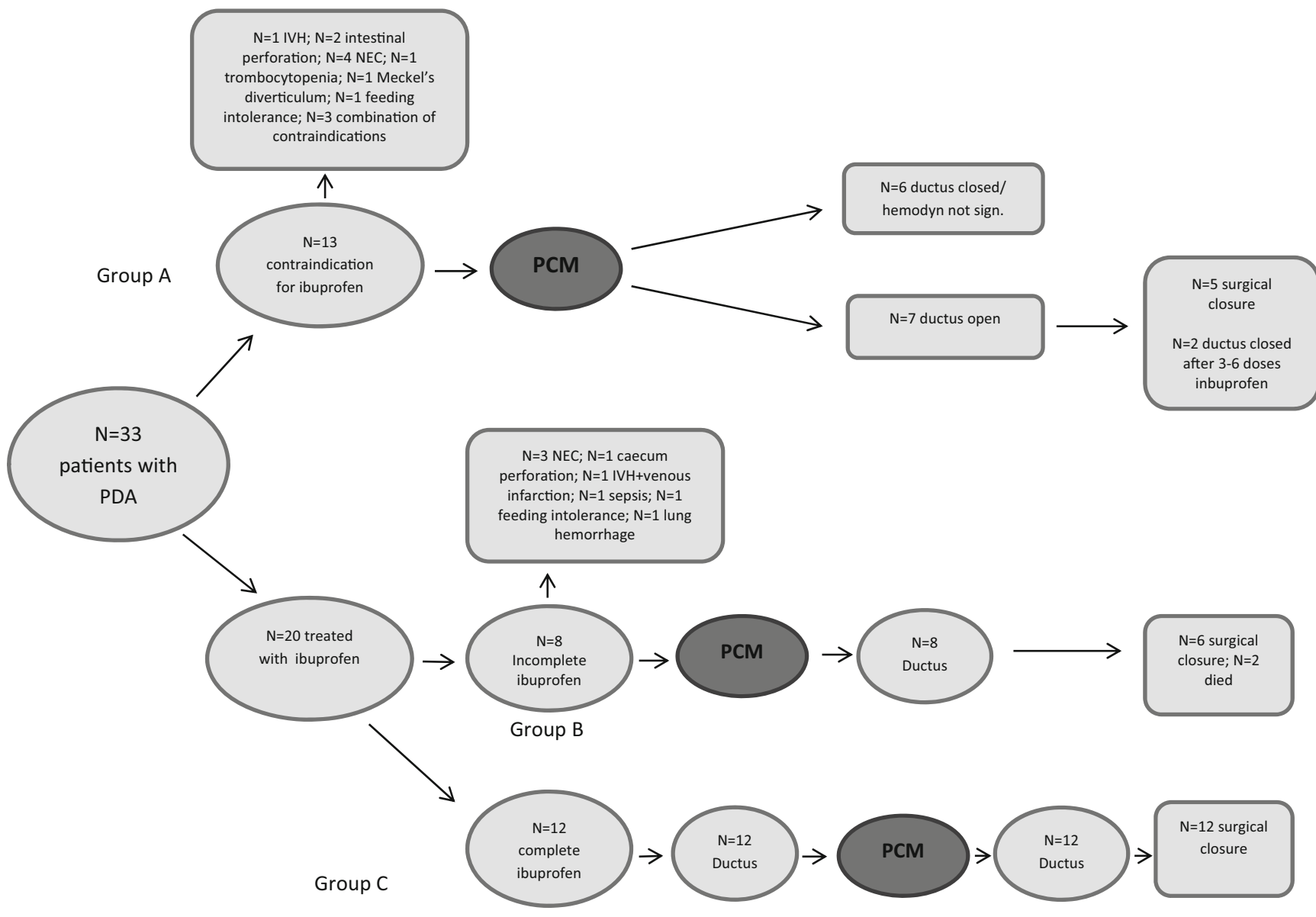

Fig. 1 Flowchart included patients

Patients in group B (=incomplete ibuprofen; $N=8$, $24.2 \%$ ) received the first dose of paracetamol after a median of 12.5 (IQR 14.75) postnatal days and the median duration of the course was 6.5 (IQR 2.75) days. Two patients died on the 24th and 34th postnatal day (i.e., sepsis with extension of bilateral intraventricular hemorrhage with venous infarction, gram-negative bacterial infection) after paracetamol treatment (started on day 8 and 13, respectively) before a decision could be made to treat the persistent PDA with surgical closure.

Paracetamol treatment was ineffective in the six remaining patients and all underwent surgical closure of the duct.

Patients in group C (=complete ibuprofen; $N=12,36.4 \%$ ) received paracetamol for a median of 5.5 days (IQR 4) after two courses of ibuprofen. At the start of paracetamol treatment, their median postnatal age was 16.5 (IQR 10.75) days. Paracetamol treatment was ineffective in all patients, and consequently, they all underwent surgical ligation.

Both the surgical ligation rate and the mortality rate differed between the three groups. Surgical ligation was performed in 5/13 (38.5\%) patrients in group A; 6/8 (75\%) in group B; and 12/12 (100\%) in group C (Fisher exact test for surgical ligation $p=0.001)$. In total, eight patients died (Fisher exact test for death $p=0.025): 4 / 13(31 \%)$ in group A (median 51 days; IQR 24.5); 4/8 (50 \%) in group B (median 30 days; IQR 34.3); and none in group C. Two of the four nonsurvivors in group B died from the consequences of NEC before surgical closure of the PDA could be performed.

Cardiac ultrasound studies showed a statistically significant decrease in ductal diameter after paracetamol treatment only in group A, from median 2.4 to $1.8 \mathrm{~mm}$ after 7 days of treatment ( $p=0.035$, paired $t$ test) (Fig. 2).

All pre- and posttreatment measurements of kidney function (urea and creatinine) and liver function (transaminases, conjugated bilirubin) were normal.

\section{Discussion}

In this study, high-dose intravenous paracetamol for the treatment of hsPDA in VLBW infants was overall effective in only $18 \%$. Looking at the subgroups of patients, paracetamol treatment was completely ineffective after previous ibuprofen treatment failure. However, it was effective in $46 \%$ of the newborns with primary contraindications for ibuprofen. 
Table 2 Background characteristics

\begin{tabular}{|c|c|c|c|}
\hline Characteristics & $\begin{array}{l}\text { Group A } \\
N=13\end{array}$ & $\begin{array}{l}\text { Group B } \\
N=8\end{array}$ & $\begin{array}{l}\text { Group C } \\
N=12\end{array}$ \\
\hline Gestational age (weeks); median & 25.2 & 24.3 & 25.8 \\
\hline Range & $24.0-26.4$ & $24.0-26.3$ & $23.6-26.6$ \\
\hline IQR & 0.8 & 0.7 & 1.0 \\
\hline Birth weight $(\mathrm{g})$ : median & 650 & 730 & 868 \\
\hline Range & $400-1130$ & $365-820$ & $480-990$ \\
\hline IQR & 360.0 & 305.0 & 231.3 \\
\hline Small for gestational age: $n(\%)$ & $5(38.5)$ & $3(37.5)$ & $2(16.7)$ \\
\hline \multicolumn{4}{|l|}{ Gender } \\
\hline Male: $n(\%)$ & $9(69.2)$ & $4(50)$ & $6(50)$ \\
\hline Female: $n(\%)$ & $4(30.8)$ & $4(50)$ & $6(50)$ \\
\hline Died: $n(\%)$ & $4(30.8)$ & $4(50)$ & $0(0)$ \\
\hline Post natal age: median/IQR & $51 / 24.5$ & $30 / 34.3$ & \\
\hline Antenatal steroids: $n(\%)$ & $11(84.6)$ & $8(100)$ & $12(100)$ \\
\hline PIH: $n(\%)$ & $3(23.1)$ & $2(25)$ & $2(16.7)$ \\
\hline Cesarean section: $n(\%)$ & $9(69.2)$ & $5(62.5)$ & $7(58.3)$ \\
\hline Mechanical ventilation: $n(\%)$ & $12(92.3)$ & $7(87.5)$ & $11(91.7)$ \\
\hline Surfactant treatment & $10(76.9)$ & $7(87.5)$ & $11(91.7)$ \\
\hline Diuretics & $11(84.6)$ & $4(50)$ & $11(91.7)$ \\
\hline Fluid restriction & $9(69.2)$ & $3(37.5)$ & $8(66.7)$ \\
\hline PNA start PCM: median (days) & 12.0 & 12.5 & 16.5 \\
\hline IQR & 11.5 & 14.75 & 10.75 \\
\hline Paracetamol treatment & 6.0 & 6.5 & 5.5 \\
\hline Days in total (median/IQR) & 3 & 2.75 & 4 \\
\hline Surgical ligation: $n(\%)$ & $5(38.5)$ & $6(75.0)$ & $12(100)$ \\
\hline PDA diameter before start PCM (mm): median/IQR & $2.4 / 1.30$ & $1.9 / 1.13$ & $.4 / 0.83$ \\
\hline PDA diameter after 3 days PCM (mm): median/IQR & $1.9 / 0.90$ & $2.1 / 1.13$ & $2.1 / 1.08$ \\
\hline PDA diameter after 7 days PCM (mm): median/IQR & $1.8 / 1.28$ & $2.0 / 0.40$ & $2.6 / 1.60$ \\
\hline PDA:LPA ratio before start PCM median/IQR & $0.85 / 0.55$ & $0.85 / 0.45$ & $0.90 / 0.30$ \\
\hline PDA:LPA ratio after 3 days PCM median/IQR & $0.90 / 0.60$ & $0.80 / 0.15$ & $0.95 / 0.50$ \\
\hline PDA:LPA ratio after 7 days PCM median/IQR & $0.75 / 0.58$ & $0.80 / 0.30$ & $0.85 / 0.28$ \\
\hline LA/Ao ratio before start PCM median/IQR & $1.6 / 0.30$ & $1.7 / 0.53$ & $1.75 / 0.30$ \\
\hline LA/Ao ratio after 3 days PCM median/IQR & $1.64 / 0.60$ & $1.7 / 0.70$ & $1.8 / 0.55$ \\
\hline LA/Ao ratio after 7 days PCM median/IQR & $1.4 / 0.55$ & $1.9 / 0.40$ & $1.7 / 0.65$ \\
\hline NT-proBNP $(\mathrm{pmol} / 1)^{\mathrm{a}}$ : median & 1097 & 2102 & 3078 \\
\hline IQR & 3849.3 & 5832.0 & 4981.8 \\
\hline
\end{tabular}

PIH pregnancy induced hypertension syndrome, $P N A$ postnatal age, $P C M$ paracetamol, $L P A$ left pulmonary artery, $L A$-Ao left atrium-Aorta, NT-proBNP $\mathrm{N}$-terminal pro-brain natriuretic peptide

${ }^{\text {a }}$ All NT-proBNP values were determined on day 3 PNA

The variability in success rates of this paracetamol therapy for PDA closure is hard to explain. Other studies reported success rates of 0 [7] up to $100 \%[12,19]$. Success rates in two RCTs comparing oral paracetamol versus oral ibuprofen were 81 [5] and $94 \%$ [20], respectively, thus, much higher than in our study. Still, in all but one of those studies, the same dosing regimen of $60 \mathrm{mg} / \mathrm{kg} / 24 \mathrm{~h}$ paracetamol was used. In the study by Tekgunduz et al. the dose was lowered to $30 \mathrm{mg} / \mathrm{kg} /$ day after a patient showed elevated transaminases [13]. The duration of paracetamol treatment in our study was 6.0 days compared to 4.1 days [29] and 3.9 days [19] in the studies with high success rates.

In previous studies, except in the two RCTs [5, 20], the indication for paracetamol was the same as in our study (treatment failure or contraindication for ibuprofen). The interpretation of different studies on this subject seems to be hindered by the lack of an international guideline on the definition of hsPDA and cutoff values 
Fig. 2 Change in ductus arteriosus diameter after 3 to maximum 7 days of intravenous PCM treatment for the three different groups (group A: primary contraindication for ibuprofen; group B: paracetamol after early stop of ibuprofen; and group C: paracetamol after complete ibuprofen treatment)

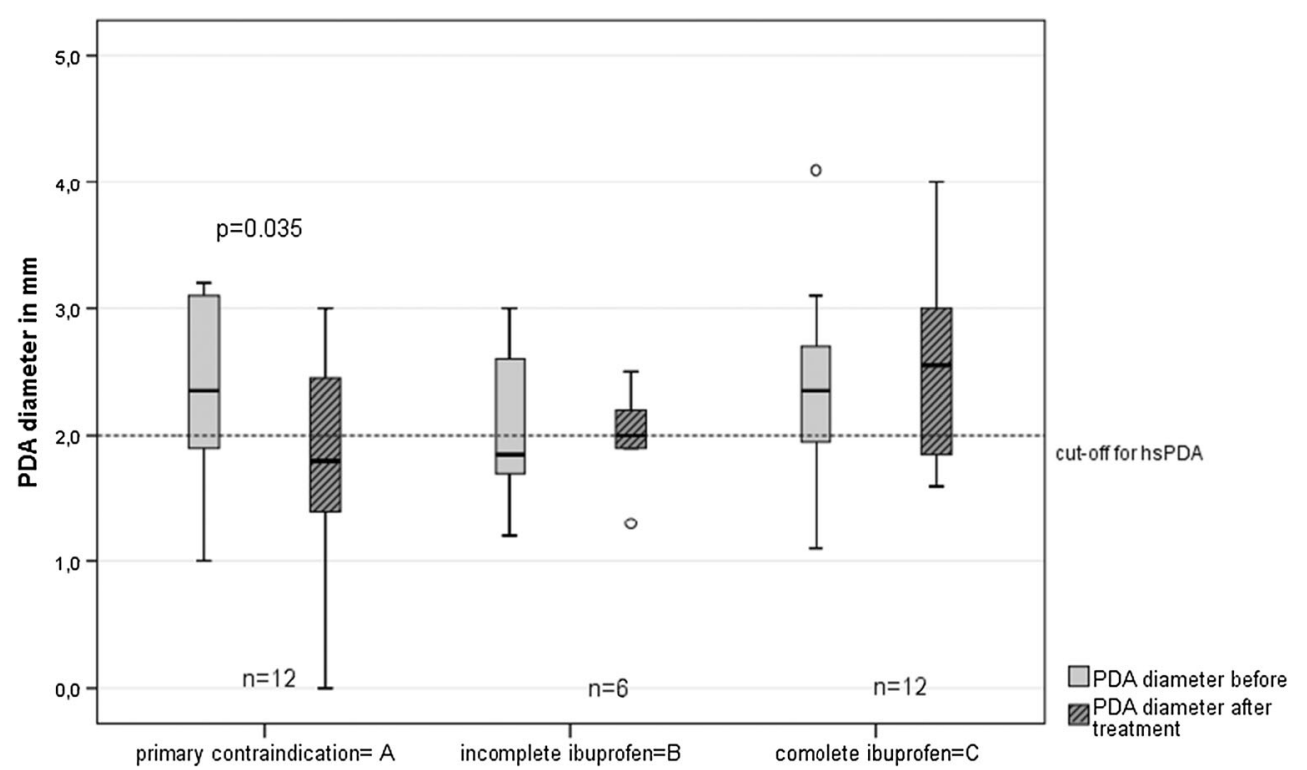

for a small, medium, or large PDA (cardiac ultrasound measurements).

It is remarkable that Oncel et al. reported a $100 \%$ success rate of PDA closure with intravenous paracetamol [19], the same administration route as in our study. Although unlikely, the route of administration could in part explain the variety in success rates; as long as data on bioavailability of the drug in the different routes and enterohepatic recirculation are lacking, we cannot tell which route of administration is superior. Still, ibuprofen studies also tend to find better results with oral administration [27]. Intravenous therapy probably leads to high peak plasma levels, but on the other hand, also to a relatively fast decrease in levels. Oral therapy might result in lower but more steady plasma levels. It can be hypothesized that PDA closure relies more on continuous prostaglandin inhibition than on intermittent high paracetamol or NSAIDs levels.

The relatively late start of paracetamol administration might be the most important explanation for our disappointing results compared to other studies. A second likely reason is the low gestational ages in our study. Other studies with better results $[12,19,21,29]$ included older infants with gestational ages $>28$ weeks. PDAs in this age group are generally less hemodynamically significant and tend to close spontaneously and respond better to pharmacological treatment.

Ibuprofen therapy failure was previously found to be $17 \%$ in infants with gestational ages of $26-27$ weeks versus $62 \%$ in 23-25-week-old infants [6]. PDAs in more preterm born infants are probably less responsive to cyclooxygenase inhibitors due to higher expression of prostaglandin receptors [3]. Next to gestational age and postnatal age, clinical factors such as the amount of fluids given, incidence of infections or sepsis, type of respiratory support, and use of co-medication might be influential factors for PDA closure success in extreme preterm infants.

Third, selection bias may have occurred, in that, we included patients in whom ibuprofen therapy had failed prior to paracetamol treatment. As NSAIDs are more potent prostaglandin synthesis inhibitors than paracetamol [8], resulting in lower peripheral PGE2 levels as is shown in orthodontic studies [25], the a priori probability of success of paracetamol in this group of patients was already relatively low.

Pharmacokinetics and pharmacodynamics of paracetamol for PDA closure have been hardly studied. Consequently, the effective plasma level of paracetamol to achieve PDA closure is unknown. The currently used dosages are already much higher than recommended for analgesia, and might be unsafe. Increasing the dose to improve closure rates is unadvisable. In a study by Kessel et al., plasma levels of paracetamol $(15 \mathrm{mg} / \mathrm{kg} / 6 \mathrm{~h}$ by nasogastric tube) did not exceed the recommended plasma levels of $10-20 \mathrm{mg} / \mathrm{l}$ for pain and fever control [14]. Based on predictive modeling, plasma levels will accumulate with the $15 \mathrm{mg} / \mathrm{kg} / 6 \mathrm{~h}$ regimen, reaching peaks of nearly $25 \mathrm{mg} / \mathrm{kg}$ after four doses [1]. In very preterm infants and murine studies, the effectiveness of paracetamol on PDA closure was suggested to depend on dosing, duration of treatment ( $>2$ days course), and mode of administration [8].

Likewise, safety of paracetamol in very preterm infants (gestational age $<28$ weeks) has been little studied. Allegaert et al. showed no hemodynamic alterations during and following an intravenous loading dose of paracetamol and afebrile neonates maintained normothermia [2]. Paracetamol-induced hepatotoxicity is the most important concern; this is caused by the formation of a highly active metabolite $N$-acetyl- $p$-benzoquinone imine (NAPQ1) by the hepatic cytochrome P450dependent CYP2E1 enzyme system [28]. The formation of 
NAPQ1 is suggested to be low due to the immaturity of the hepatic enzymes, although increased susceptibility to toxicity from supratherapeutic paracetamol is described in infants and younger children with fever [13]. CYP2E1 activity has not yet been quantified in neonates and the correlation between paracetamol concentration and increased NAPQ1 production is unknown.

Several limitations of this study should be addressed. First, this was an observational single center study with relatively few patients per group, without a matched control group to rule out spontaneous PDA closure. Firm statements are therefore difficult to make. Second, the echocardiosonographer and pediatric cardiologist were not blinded for the PDA treatment. Third, only patients were included in our study after ibuprofen failure or with a primary or secondary contraindication for ibuprofen; this selection bias might have contributed to our results.

\section{Conclusions}

In view of the findings from this study, we do not recommend the use of intravenous paracetamol for hsPDA closure in VLBW infants after ibuprofen failure. Still, as we did not rule out effectiveness of paracetamol as early PDA treatment, it might be recommended when started in the first week of life. On the other hand, as long as data on long term safety are lacking, high dosages of paracetamol should be used with caution. Better designed PK/PD studies are needed to shed a light on safety aspects and the optimal dose-concentrationeffect relationship. PK modeling of available data on PDA treatment with paracetamol in different gestational age groups can lead to different dosing recommendations per age group; a trial with these dose recommendations of paracetamol for PDA is also an option for future research.

Acknowledgments We thank J. Hagoort (Erasmus MC - Sophia Children's Hospital) for editorial assistance.

Conflict of interest All authors have nothing to disclose of potential conflicts of interest.

Compliance with ethical standards The research involved human participants.

Paracetamol treatment is part of our routine treatment guidelines for PDA treatment, and this study was an observational study. With the approval of the Medical Ethical Committee of our hospital (registration number MEC-2013-138), no informed consent was asked. To perform ongoing safety surveillance and to perform interim analyses on the safety data, an independent Data Safety Monitoring Board was assigned. The committee consisted of a pediatric intensivist, a hospital pharmacist and a neonatologist (from another NICU in the Netherlands). They had no involvement in or contact with the patients.

Authors' contribution Dr. Roofthooft conceptualized and designed the study, designed the data collection instruments, coordinated and supervised data collection at the site, carried out the initial analyses, drafted the initial manuscript, and approved the final manuscript as submitted.

Dr. van Beynum and Dr. de Klerk carried out the cardiac ultrasounds and analyzed them. Furthermore, they reviewed and revised the manuscript, and approved the final manuscript as submitted.

Dr. Tibboel, Dr. van den Anker, and Dr Reiss critically reviewed and revised the manuscript, and approved the final manuscript as submitted.

Dr. van Dijk and Dr Simons conceptualized and designed the study, designed the data collection instruments, carried out the initial analyses, critically reviewed and revised the manuscript, and approved the final manuscript as submitted.

Open Access This article is distributed under the terms of the Creative Commons Attribution 4.0 International License (http:// creativecommons.org/licenses/by/4.0/), which permits unrestricted use, distribution, and reproduction in any medium, provided you give appropriate credit to the original author(s) and the source, provide a link to the Creative Commons license, and indicate if changes were made.

\section{References}

1. Alan S, Karadeniz C, Okulu E, Kilic A, Erdeve O, Ucar T, Atasay B, Atalay S, Arsan S (2013) Management of patent ductus arteriosus in preterm infants: clinical judgment might be a fair option. J Matern Fetal Neonatal Med 26:1850-1854

2. Allegaert K, Naulaers G (2010) Haemodynamics of intravenous paracetamol in neonates. Eur J Clin Pharmacol 66:855-858

3. Bouayad A, Kajino H, Waleh N, Fouron JC, Andelfinger G, Varma DR, Skoll A, Vazquez A, Gobeil F Jr, Clyman RI, Chemtob S (2001) Characterization of PGE2 receptors in fetal and newborn lamb ductus arteriosus. Am J Physiol Heart Circ Physiol 280: H2342-H2349

4. Bozdag SC, Tekgunduz E, Durgun G, Sarica A, Demiriz IS, Kocubaba S, Altuntas F (2013) Which regimen is better for stem cell mobilization of lymphoma patients? Transfus Apher Sci 48: $407-410$

5. Dang D, Wang D, Zhang C, Zhou W, Zhou Q, Wu H (2013) Comparison of oral paracetamol versus ibuprofen in premature infants with patent ductus arteriosus: a randomized controlled trial. PLoS One 8:e77888

6. Dani C, Bertini G, Corsini I, Elia S, Vangi V, Pratesi S, Rubaltelli FF (2008) The fate of ductus arteriosus in infants at 23-27 weeks of gestation: from spontaneous closure to ibuprofen resistance. Acta Paediatr 97:1176-1180

7. Demiriz IS, Bozdag SC, Tekgunduz E, Ugur B, Durgun G, Kocubaba S, Altuntas F (2013) Predicting the successful peripheral blood stem cell harvesting. Transfus Apher Sci 48:411-414

8. El-Khuffash A, Jain A, Corcoran D, Shah PS, Hooper CW, Brown N, Poole SD, Shelton EL, Milne GL, Reese J, McNamara PJ (2014) Efficacy of paracetamol on patent ductus arteriosus closure may be dose dependent: evidence from human and murine studies. Pediatr Res 76:238-244

9. El-Khuffash A, James AT, Cleary A, Semberova J, Franklin O, Miletin J (2015) Late medical therapy of patent ductus arteriosus using intravenous paracetamol. Arch Dis Child Fetal Neonatal Ed

10. Evans N, Kluckow M (1996) Early ductal shunting and intraventricular haemorrhage in ventilated preterm infants. Arch Dis Child Fetal Neonatal Ed 75:F183-F186

11. Hammerman C, Bin-Nun A, Kaplan M (2012) Managing the patent ductus arteriosus in the premature neonate: a new look at what we thought we knew. Semin Perinatol 36:130-138 
12. Hammerman C, Bin-Nun A, Markovitch E, Schimmel MS, Kaplan M, Fink D (2011) Ductal closure with paracetamol: a surprising new approach to patent ductus arteriosus treatment. Pediatrics 128:e1618-e1621

13. Heubi JE, Barbacci MB, Zimmerman HJ (1998) Therapeutic misadventures with acetaminophen: hepatoxicity after multiple doses in children. J Pediatr 132:22-27

14. Kessel I, Waisman D, Lavie-Nevo K, Golzman M, Lorber A, Rotschild A (2014) Paracetamol effectiveness, safety and blood level monitoring during patent ductus arteriosus closure: a case series. J Matern Fetal Neonatal Med 27:1719-1721

15. Kluckow M, Evans N (2000) Ductal shunting, high pulmonary blood flow, and pulmonary hemorrhage. J Pediatr 137:68-72

16. Koch J, Hensley G, Roy L, Brown S, Ramaciotti C, Rosenfeld CR (2006) Prevalence of spontaneous closure of the ductus arteriosus in neonates at a birth weight of 1000 grams or less. Pediatrics 117 : $1113-1121$

17. Mandhan P, Brown S, Kukkady A, Samarakkody U (2009) Surgical closure of patent ductus arteriosus in preterm low birth weight infants. Congenit Heart Dis 4:34-37

18. Noori S, McCoy M, Friedlich P, Bright B, Gottipati V, Seri I, Sekar $\mathrm{K}$ (2009) Failure of ductus arteriosus closure is associated with increased mortality in preterm infants. Pediatrics 123:e138-e144

19. Oncel MY, Yurttutan S, Degirmencioglu H, Uras N, Altug N, Erdeve O, Dilmen U (2013) Intravenous paracetamol treatment in the management of patent ductus arteriosus in extremely low birth weight infants. Neonatology 103:166-169

20. Oncel MY, Yurttutan S, Erdeve O, Uras N, Altug N, Oguz SS, Canpolat FE, Dilmen U (2014) Oral paracetamol versus oral ibuprofen in the management of patent ductus arteriosus in preterm infants: a randomized controlled trial. J Pediatr 164:510-514, e511

21. Oncel MY, Yurttutan S, Uras N, Altug N, Ozdemir R, Ekmen S, Erdeve O, Dilmen U (2013) An alternative drug (paracetamol) in the management of patent ductus arteriosus in ibuprofen-resistant or contraindicated preterm infants. Arch Dis Child Fetal Neonatal Ed 98:F94
22. Patel J, Roberts I, Azzopardi D, Hamilton P, Edwards AD (2000) Randomized double-blind controlled trial comparing the effects of ibuprofen with indomethacin on cerebral hemodynamics in preterm infants with patent ductus arteriosus. Pediatr Res 47:36-42

23. Pezzati M, Vangi V, Biagiotti R, Bertini G, Cianciulli D, Rubaltelli FF (1999) Effects of indomethacin and ibuprofen on mesenteric and renal blood flow in preterm infants with patent ductus arteriosus. J Pediatr 135:733-738

24. Roofthooft DW, van Beynum IM, Helbing WA, Reiss IK, Simons SH (2013) Paracetamol for ductus arteriosus closure: not always a success story. Concerning the article by M. Y. Oncel et al.: intravenous paracetamol treatment in the management of patent ductus arteriosus in extremely low birth weight infants [Neonatology 2013; 103:166-169]. Neonatology 104:170

25. Shetty N, Patil AK, Ganeshkar SV, Hegde S (2013) Comparison of the effects of ibuprofen and acetaminophen on PGE2 levels in the GCF during orthodontic tooth movement: a human study. Prog Orthod 14:6

26. Sinha R, Negi V, Dalal SS (2013) An interesting observation of PDA closure with oral paracetamol in preterm neonates. J Clin Neonatol 2:30-32

27. Tekgunduz KS, Ceviz N, Demirelli Y, Olgun H, Caner I, Sahin IO, Yolcu C (2013) Intravenous paracetamol for patent ductus arteriosus in premature infants - a lower dose is also effective. Concerning the article by M. Y. Oncel et al.: intravenous paracetamol treatment in the management of patent ductus arteriosus in extremely low birth weight infants [Neonatology 2013; 103:166169]. Neonatology 104:6-7

28. Van Eyken P, Nemolato S, Faa G, Ambu R (2012) Hepatic injury to the newborn liver due to drugs. Curr Pharm Des 18:3050-3060

29. Yurttutan S, Oncel MY, Arayici S, Uras N, Altug N, Erdeve O, Dilmen U (2013) A different first-choice drug in the medical management of patent ductus arteriosus: oral paracetamol. J Matern Fetal Neonatal Med 26:825-827 